\title{
Uşak İli Çevresindeki Depremlerin Yapay Sinir Ağları ile Modellenmesi
}

\author{
Elif Çağda KANDEMİR MAZANOĞLU*1 \\ 1Uşak Üniversitesi, Mühendislik Fakültesi, İnşaat Mühendisliği Bölümü, 64200, Uşak
}

(Alınış / Received: 04.08.2016, Kabul / Accepted: 07.02.2017, Online Yayınlanma / Published Online: 02.05.2017)

Anahtar Kelimeler Özet: Deprem Bölgelerinde Yapılacak Binalar Hakkında Yapay Sinir Ağları, Yönetmelik 2007 (DBYBHY, 2007)'de, Uşak ilinin büyük bir kısmı Maksimum Yer İvmesi, İleri Beslemeli Geri-Yayılım Algoritması 2. derece deprem bölgesinde olup, Eşme ilçesi 1. derece deprem bölgesinde bulunmaktadır. Ancak il sınırlarına yakın çevrede bulunan Kütahya'ya bağlı Gediz, Simav ve Afyon'a bağlı Dinar ilçelerindeki uzun ve aktif faylarda meydana gelen depremler, Uşak il ve ilçelerinde önemli ölçüde hissedilmekte ve etkileri gözlenmektedir. Buna karşın il sınırları içerisinde, biri merkezde diğeri Eşme'de olmak üzere yalnızca 2 adet deprem kayıt istasyonu bulunmaktadır. Çalışmada hedeflenen, çevredeki deprem kayıt istasyonlarında ölçülmüş kayıtlar kullanılarak, yapay sinir ağları (YSA) modelleri oluşturmak ve il sınırları içinde istasyon olmayan bölgelerdeki en büyük yer ivmesi tahmini yapabilmektir. Oluşturulan modeller kullanılarak istasyon olan merkez ilçede meydana gelmiş en yüksek ivme değerleri tahmin edilmiş ve ölçülmüş veriler ile karşılaştırılmış, böylece modellerin doğruluğu irdelenmiștir. Buna ek olarak, tüm ilçeler için elde edilen en büyük yer ivmesi değerleri DBYBHY 2007'de öngörülen değerler ile kıyaslanmıştır.

\section{Artificial Neural Network Modelling of Earthquakes around Usak City}

\section{Keywords}

Artificial Neural

Network,

Peak Ground

Acceleration,

Feed Forward

Back-Propagation

Algorithm
Abstract: In Turkish Earthquake Code 2007 (TEC, 2007), Usak city is located in the second-degree seismic zone while Esme, a town and district of Usak Province, is in the first-degree seismic zone. However cities in neighbourhood of Usak, such as Gediz, Simav towns of Kütahya city and Dinar district of Afyon city have many active faults which led to severe seismic damages in and around Usak. Despite this, Usak has only 2 active seismic stations which are in Usak city centre and Esme town. This paper aims to constitute artificial neural network (ANN) models by using seismic data of neighbour stations and to estimate peak ground acceleration (PGA) in the districts without stations. The results of models are validated by comparing the predicted and measured seismic data of the Usak central station. In addition, PGAs obtained by models are compared with design values in TEC 2007. 


\section{Giriş}

Uşak ili, depremin yıkıcı etkisinin fazla yaşanmadığı illerden biridir. İl sınırları, nüfus açısından büyükten küçüğe merkez, Banaz, Eşme, Sivaslı, Ulubey ve Karahallı ilçelerinden oluşmaktadır. DBYBHY 2007'de [1] etkin yer ivmesi katsayıları $\left(\mathrm{A}_{0}\right)$ deprem bölgelerine göre belirlenmekte olup, 1996 yılında yürürlüğe giren Türkiye Deprem Bölgeleri Haritası'na [2] göre Uşak ilinde Eşme ilçesi 1. derece deprem bölgesi olup diğer tüm ilçeler 2. derece deprem bölgesi olarak tayin edilmiştir. Ayrıca ilde, biri merkezde biri Eşme'de olmak üzere 2 adet aktif deprem kayıt istasyonu bulunmaktadır. Geçmişte Uşak, il sınırları içerisindeki faylardan meydana gelmiş şiddetli depremlere maruz kalmamış olsa bile, Kütahya'ya bağlı Gediz, Simav ve Afyon'a bağlı Dinar ilçelerinde bulunan uzun ve aktif faylarda meydana gelen depremler, Uşak il ve ilçelerinde önemli ölçüde hissedilmiş ve etkileri gözlenmiştir. $\mathrm{Bu}$ nedenle bu çalışmada, sismik aktivitesi daha fazla olan yakın çevrenin deprem kayit istasyonlarından elde edilen veriler kullanılarak, Uşak'ta istasyon olmayan bölgelerde maksimum yer ivmelerinin (MYI) tahmin edilmesi amaçlanmaktadır.

Belirli bir bölgeye ait deprem kayıtları, o bölgenin sismik aktivitesini değerlendirmek ve yapıların tasarım standartlarını belirlemek için gerek duyulan önemli verilerdir. Bir depremin maksimum yer ivmesi (MYI) (peak ground acceleration-PGA) depremi tanımlayan en önemli parametrelerden biridir. Literatürde MYİ tahminine yönelik pek çok çalışma bulunmaktadır [3-9].

Sismik parametreler gibi, parametreleri arasında doğrudan formülize edilebilecek bağıntının tanımlanamadığı problemlerde, yapay sinir ağları yaklaşımı ile rahatlıkla çözüm üretilebilmektedir. Yapay sinir ağları, yapay zekânın alt birimi olan makine öğrenmesi kapsamında geliștirilmiştir. Olayın örnekleri, bilgisayara girdi ve çlktı olarak sunulur ve makine, aralarındaki ilişkiyi öğrenerek eğitilir. Böylece model zaman içerisinde oluşacak yeni örneklerin girdilerine göre çıktılar üretebilmekte, öngörülerde bulunabilmektedir. Özellikle, problemin parametreleri arasında bağıntının tanımlanamadığı durumlarda, tüm bilgininin bilgisayara tanıtılması şartıyla, yapay sinir ağları yaklaşımı çözüm üretilebilmektedir. Bu yaklaşım sismik veri analizinde slklıkla kullanılmaktadır [10-19]. Kerh ve Ting çalışmasında, Tayvan'daki bir hızlı tren hattı etrafında meydana gelmiş depremlerin verilerini kullanarak yapay sinir ağları modeli oluşturmuş ve modelin doğruluğunu saha ölçümleriyle kanıtlayarak, hızlı tren hattında gözlenebilecek sismik ivme tahminleri yapmiştır [20]. Gandomi vd., benzetilmiș tavlama (simulated annealing) ile yapay sinir ağları metodunu birleştirerek MYI'ni çeşitli deprem parametreleri ile ilişkilendirmişlerdir [21]. Lee ve Hal, yapay depremler ve davranış spektrumu üretmek amacıyla beș farklı yapay sinir ağları modeli geliștirmiștir [22]. Ayrıca yine yapay sinir ağları metodu kullanılarak, MYİ tahmini yapılması pek çok çalışmanın konusunu olşturmaktadır [23-25].

$\mathrm{Bu}$ çalıșmada, yapay sinir ağları modelinin fonksiyonu olarak depremin büyüklüğü, derinliği ve istasyon ile episantr arasındaki mesafe ele alınmış ve kuzey-güney (KG), doğu-batı (DB) ve düşey yönlerinde meydana gelen MYİ değerleri hesaplanmıştır. Uygulama alanı olarak, biri merkezde diğeri Eşme ilçesinde olmak üzere toplam 2 adet deprem kayit istasyonuna sahip ve şimdiye kadar deprem veri analizi yapılmamış olan Uşak ili seçilmiştir. 
Ayrıca ilin, deprem faaliyetlerinin yoğun olduğu bölgelere yakın olması da bu çalışmayı gerçekleștirmede teşvik edici unsur oluşturmuştur.

\section{Yapay Sinir Ağları}

Yapay sinir ağları (YSA), beyinde bulunan sinir hücrelerinden esinlenilerek önerilmiş bir yöntemdir. Bir sinir hücresi, diğer adıyla nöron, Şekil 1'de verildiği gibi [26], bilgiyi alan dendrid, gelen bilginin diğer nöronlara aktarımını sağlayan sinaps, bilginin geçiş yolu aksondan oluşmaktadır. Böylelikle, nörona verilen bir sinyal, birçok biyolojik nöronun bir araya gelmesiyle bilgiye dönüşmektedir.

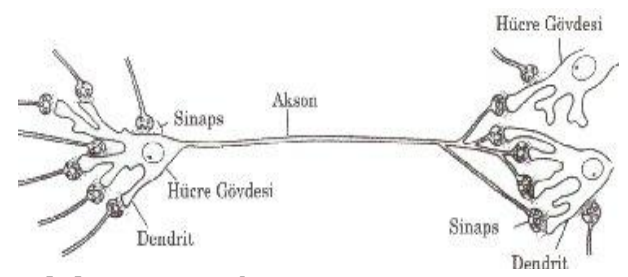

Şekil 1. Bir sinir hücresi

Yapay sinir ağları, yapay zekânın alt birimi olan makine öğrenmesi kapsamında geliştirilmiştir. Olayın örnekleri, bilgisayara girdi ve çıtı olarak sunulur ve makine, aralarındaki ilişkiyi öğrenerek eğitilir. Böylece model zaman içerisinde oluşacak yeni örneklerin girdilerine göre çıtılar üretebilmekte, öngörülerde bulunabilmektedir. Sözü edilen biyolojik sistem, yapay olarak düşünüldüğünde Şekil 2'deki yapı ortaya çıkmaktadır.

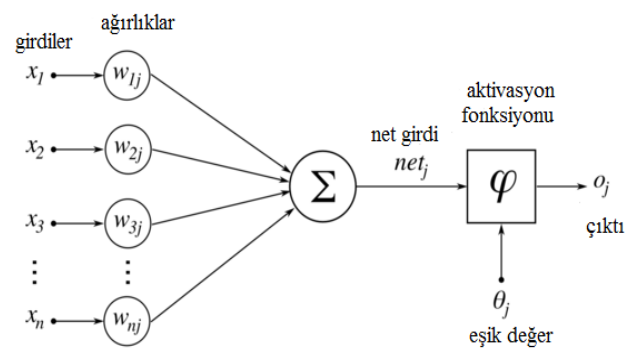

Şekil 2. Yapay nöron modeli
Şekil 2'de, girdiler $\left(x_{1}, x_{2} \ldots x_{n}\right)$ $w_{1 j}, w_{2 j} \ldots w_{n j}$ ile ağırlıklandırılarak net girdi $\left(\sum=\right.$ net $\left._{j}\right)$ oluşturulur ve net girdi aktivasyon fonksiyonu $(\varphi)$ aracıllğıla eşik değerden $\left(\theta_{j}=1\right)$ yüksek değere sahip olan çıtıtı değere $\left(o_{j}\right)$ dönüşmektedir. Eğer eşik değeri aşacak büyüklükte çıktı elde edilemezse, ağırlıklar güncellenerek yeni bir net girdi elde edilerek aktivasyon fonksiyonuna dahil edilir ve çıktı eşik değerinden büyük olana kadar iterasyon tekrar edilir. $\mathrm{Bu}$ süreç ağın eğitimi olarak adlandırılır. Verilen bu model, YSA'nın en temel modelidir. Modelin eğitilmesi için birkaç adım denemek gerekli olup, her adımda ağırlık değerleri değiștirilerek yeni bir çıktı değeri oluşturulur. Burada önemli olan tahmin ile hedef değeri arasındaki yakınlıktır. En yakın sonucu veren model en iyi model olarak kabul edilir. Çalışmamızda YSA'nın ileri-beslemeli geri yayılım algoritmasina değinilmektedir.

Yapay sinir ağları modellemesinde kullanılan tek katmanlı modellerin doğrusal olmayan problemler için yetersiz olması nedeniyle, çok katmanlı ağların kullanılması önerilmektedir [27]. Şekil 3'de çok katmanlı ileribeslemeli modelin yapısı gösterilmektedir.

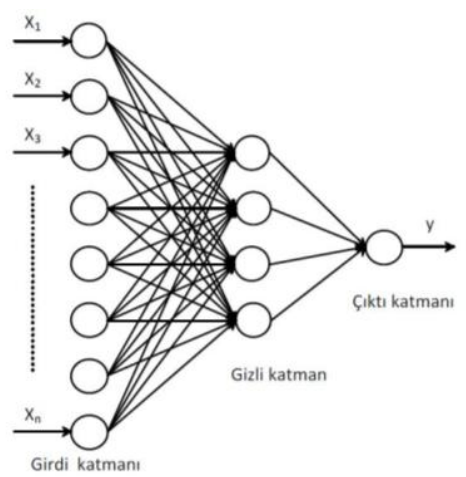

Şekil 3. Çok katmanlı ileri beslemeli YSA modeli 
Katmanlar sirasıyla, girdilerden $\left(x_{1}, x_{2} \ldots x_{n}\right)$ oluşan girdi katmanı, girdilerin önemli özelliklerini ayıran gizli katman, çıtkların oluştuğu çıktı katmanı $(y)$ olarak adlandırılmaktadır. Ağın eğitimi aşamasında girdi verileri üzerinde ağın hatası oluştuğunda, ağırlıkların değișimi zorlașmaktadır. Bu sorunu ortadan kaldırmak için geri yayılım algoritması kullanılmaktadır.

İleri-beslemeli geri yayılım algoritması p. girdi nöronu için aşağıdaki gibi verilmektedir.

1. p. girdinin i. dügüumü verisi $x_{p, i}$ olsun

2. Gizli katmandaki j. düğümün NET girdisi $n e t_{j}^{(1)}=\sum_{i=0}^{n} w_{j, i}^{(1,0)} x_{p, i}$ olup $w_{j, i}^{(1,0)}$

i. girdi katmanı ile j. gizli katman arasındaki ağırlık değeri olsun.

3. Gizli katmanın j. düğümüne ait çıktı $x_{p, j}^{(1)}=\delta\left(\sum_{i=0}^{n} w_{j, i}^{(1,0)} x_{p, j}^{(1)}\right)$, burada $\delta$ aktivasyon fonksiyonudur.

4. Çıktı katmanındaki k. düğümün NET girdisi $n e t_{k}^{(2)}=\sum_{j}\left(w_{k, j}^{(2,1)} x_{p, j}^{(1)}\right)$ olarak ifade edilir. Burada $w_{k, j}^{(2,1)}$ j. gizli katman düğümü ile k. çıtı katmanı düğümü arasındaki ağırlıktır.

5. Çıktı katmanının k. düğümünün çıktısı $y_{p, k}=\delta\left(\sum_{j} w_{k, j}^{(2,1)} x_{p, j}^{(1)}\right)$ olarak belirtilir.

Burada $\delta$ aktivasyon fonksiyonunu ifade eder.

6. Son olarak, hata karesi, $\varepsilon_{p, k}^{2}=\left|d_{p, k}-y_{p, k}\right|^{2} \quad$ olarak hesaplanir. Burada $d_{p, k}$ ve $y_{p, k}$ sirasiyla beklenen ve hesaplanan çıktı değeridir.
$\mathrm{Bu}$ algoritmanın temel amacl, (1) nolu eşitlikte verilen Eşitlik 1'de verilen $E_{p}$ hatasını en küçüklemek için en uygun ağırlıkları hesaplamaktır.

$$
E_{p}=\sum_{k}\left(\varepsilon_{p, k}\right)^{2}
$$

Gradient descend algoritması ile, girdi ve gizli katman arasındaki ağırlıklar,

$$
\Delta w_{j, i}^{(1,0)} \propto\left(\frac{-\partial E}{\partial w_{j, i}^{(1,0)}}\right)
$$

ile ve gizli ve çıktı katmanları arasındaki ağırlıklar ise,

$$
\Delta w_{k, j}^{(2,1)} \propto\left(\frac{-\partial E}{\partial w_{k, j}^{(2,1)}}\right)
$$

ile güncellenmektedir [28].

\section{3. Çalışmanın Bulguları}

Bu çalışmada, Uşak ili merkez olmak üzere ortalama $110 \mathrm{~km}$ yarıçap içerisinde bulunan toplam 13 adet deprem istasyonundan, günümüze kadar kaydedilen depremlerin verileri üzerinde çalışılmıştır. Veriler, Türkiye Ulusal Kuvvetli Yer Hareketi veri tabanından çekilmiştir [29]. Tablo 1'de, ele alınan istasyonların kodları, bulunduğu il-ilçeler, kaydedilen toplam deprem sayısı ve kayıt tarihi aralığı, MYI ve en büyük depremin moment büyüklüğü $\left(\mathrm{M}_{\mathrm{w}}\right)$ gösterilmektedir. İstasyon kodlarının ilk iki hanesi bulunduğu ilin plaka kodunu göstermekte olup, diğer iki hane sırasını belirtmektedir. İstasyonlardan elde edilen kayitlar, her bir depremin ivme zaman serilerini, episantr ve istasyon koordinatlarını, derinliğini, büyüklüğünü ve $K G, \quad D B$ ve düşey yönlerdeki MYI değerlerini göstermektedir. 
E.Ç. Kandemir Mazanoğlu / Uşak İli Çevresindeki Depremlerin Yapay Sinir Ağları ile Modellenmesi

Tablo 1. Çalıșllan istasyonlar ve özellikleri

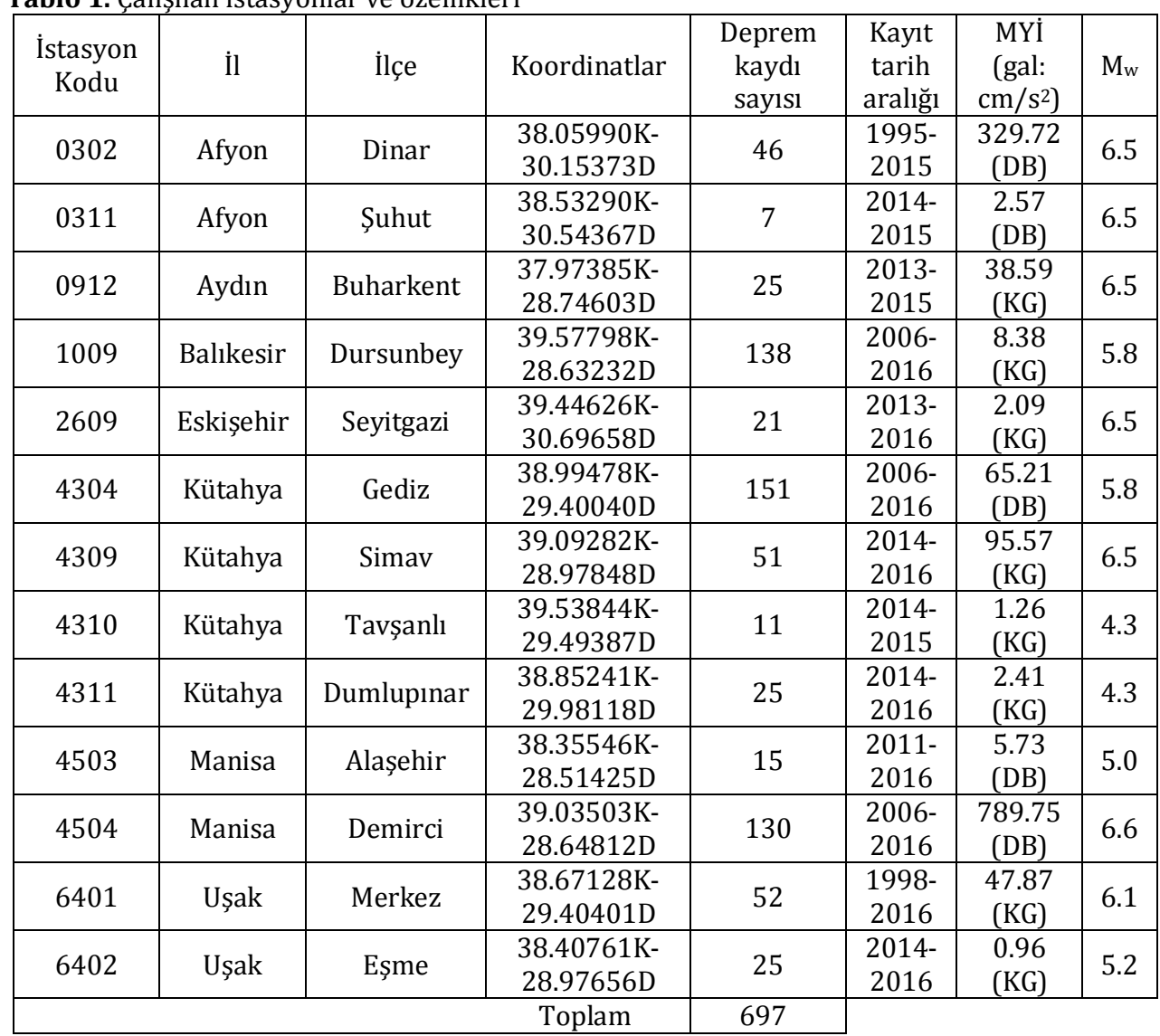

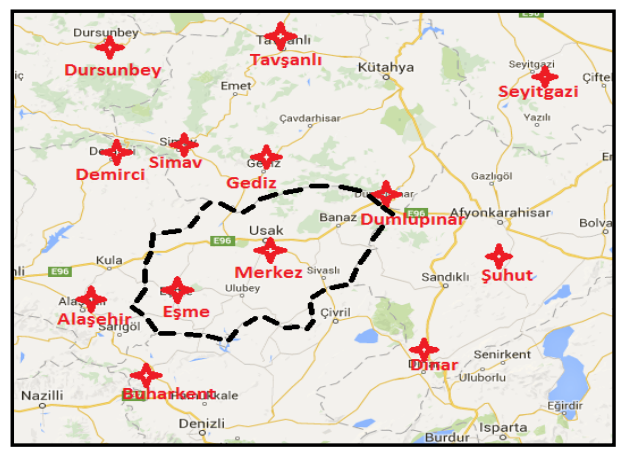

Şekil 4 Deprem istasyonlarının harita üzerindeki yerleri

Modellemeyi güçleştirecek verileri elimine etmek amaciyla, deprem verilerine üst ve alt sınırlar getirilmiştir. Böylelikle derinlik $\leq 20 \mathrm{~km}, \mathrm{M}_{\mathrm{w}} \geq 4$, episantr uzaklığı $\leq 300 \mathrm{~km}$ olan veriler, model oluşturmak amaciyla kullanılmıştır. Veri dosyalarında deprem büyüklükleri yerel büyüklük $\left(\mathrm{M}_{\mathrm{L}}\right)$ veya moment büyüklüğü $\left(\mathrm{M}_{\mathrm{w}}\right)$ cinsinden belirtilmiștir. Tüm veriler moment büyüklügüne $\quad\left(\mathrm{M}_{\mathrm{w}}\right)$ dönüştürülmüş olup, bu işlem için aşağıdaki formül kullanılmıştır [30]:

$$
M_{w}=0.97 M_{L}+0.58\left(4.5 \leq M_{L} \leq 6\right)
$$

Çalışmada, YSA modellerinin giriş katmanı depremin derinliği, moment büyüklüğü ve istasyonun episantra uzaklığından oluşurken, çıkış katmanı da MYI'den oluşmaktadır. Her bir istasyon ve deprem bileşeni için (KG, $\mathrm{DB}$, düşey) YSA modelleri olușturulmuștur. Bu durumda her bir istasyon için 3 YSA modeli olup, tüm çalışmada 39 model oluşturulmuştur. Verilerin, Eşitlik 5' te verilen ifade ile 
normalize edilerek 0 ile 1 arasında değerler alması sağlanmıștır [27].

$$
\mathrm{x}^{\prime}=\frac{\mathrm{x}-\mathrm{x}_{\min }}{\mathrm{x}_{\max }-\mathrm{x}_{\min }}
$$

$\mathrm{x}$ ele alınan parametre olup (depremin derinliği, büyüklüğü ve istasyonun episantra uzaklığ $), \mathrm{x}_{\min }$ ve $\mathrm{x}_{\max }$ sirayla, bu parametrelerin kendi içinde en küçük ve en büyük değerlerini ifade etmektedir.

Olușturulan modellerde girdi katmanı 3, gizli katman 2 ve çıktı katmanı da 1 tabakadan oluşmakta olup, gizli katmandaki nöron sayısı 10 olarak tanımlanmıștır. İleri-beslemeli Levenberg-Marquardt geri yayllım öğrenme algoritması [31] kullanılarak, girdi katmanının \%70'i eğitim verisi, \%15'i geçerlilik, \%15'i de test verisi olarak rassal olarak belirlenmiştir. Gizli katmanlar ile girdi ve çıtı katmanları arasındaki aktivasyon fonksiyonları tanjant sigmoid olarak belirlenmiștir.

\subsection{YSA Model Bulguları}

Çalışmada, YSA analizleri Matlab fonksiyonu olan nntool komutu ile gerçekleştirilmiştir. İlk aşamada her bir istasyon kendi içinde modellenmiştir. Elimine edildikten sonra kalan veri sayısı az olduğundan Afyon Şuhut istasyonu için model oluşturulamamıştır. Tablo 2'de, ağın daha iyi sonuç verebilmesi için ağın eğitiminde kullanılan geçerlilik verilerinin yüksek regresyon katsayısına sahip olduğu görülmektedir. $\mathrm{Bu}$ sonuç eğitim iterasyonları boyunca ağın çıkışı ile istenilen sonuç arasındaki farkın karesinin en fazla minimize edildiği durumu göstermektedir. Girdi katmanındaki tabakalarda değişiklik yaparak, aynı modellerden sonuç elde edilmek istendiğinde ise, girdi katmanı ile gizli katmanlar arasındaki ağırlık (weight) ve eşik (bias) değerleri sabit tutulmak kaydı ile model yeniden çalıștırılır. Bu çalıșmada, 11 istasyonun her bir deprem bileșeni için kurulan modeller kullanılarak Uşak Merkez istasyonunun hâlihazırda ölçülmüş olan verileri tahmin edilmiștir. $\mathrm{Bu}$ modellerde, 3 tabakadan oluşan girdi katmanındaki büyüklük ve derinlik parametreleri aynı tutularak, diğer tabakaya depremin ölçüldüğü episantr koordinatlarının Uşak Merkez istasyona olan uzaklığı girilmiştir. Tahmin edilen ve ölçülmüş olan (hedef) veriler arasındaki doğrusal regresyon katsayıları $\left(\mathrm{r}^{2}\right)$ Tablo 3'te gösterilmiştir.

Tablo 2. YSA modellerinin eğitimi sırasında geçerlilik verilerinin ortalama regresyon katsayıları

\begin{tabular}{|c|c|c|c|c|c|}
\hline \multirow{2}{*}{ İstasyon Kodu } & \multirow{2}{*}{ İl } & \multirow{2}{*}{ İlçe } & \multicolumn{3}{|c|}{$\mathrm{r}^{2}$} \\
\cline { 4 - 6 } & & KG & DB & Düșey \\
\hline 0302 & Afyon & Dinar & 0.927 & 0.979 & 0.982 \\
\hline 0311 & Afyon & Şuhut & - & - & - \\
\hline 0912 & Aydın & Buharkent & 0.998 & 0.919 & 0.968 \\
\hline 1009 & Balıkesir & Dursunbey & 0.966 & 0.981 & 0.925 \\
\hline 2609 & Eskişehir & Seyitgazi & 0.917 & 0.885 & 0.894 \\
\hline 4304 & Kütahya & Gediz & 0.954 & 0.915 & 0.979 \\
\hline 4309 & Kütahya & Simav & 0.943 & 0.927 & 0.916 \\
\hline 4310 & Kütahya & Tavşanlı & 0.956 & 0.914 & 0.923 \\
\hline 4311 & Kütahya & Dumlupınar & 0.968 & 0.957 & 0.934 \\
\hline 4503 & Manisa & Alaşehir & 0.975 & 0.958 & 0.935 \\
\hline 4504 & Manisa & Demirci & 0.965 & 0.977 & 0.937 \\
\hline 6401 & Ușak & Merkez & 0.933 & 0.913 & 0.975 \\
\hline 6402 & Ușak & Eşme & 0.964 & 0.910 & 0.899 \\
\hline
\end{tabular}


Tablo 3. YSA modelleri kullanılarak tahmin edilen Uşak Merkez istasyonu verilerinin regresyon katsayları

\begin{tabular}{|l|c|c|c|c|}
\hline \multirow{2}{*}{ YSA Modeli } & \multirow{2}{*}{ Tahmin Verisi } & \multicolumn{3}{|c|}{$\mathrm{r}^{2}$} \\
\cline { 3 - 5 } & & KG & DB & Düşey \\
\hline Afyon-Dinar & Ușak-Merkez & 0.912 & 0.875 & 0.847 \\
\hline Aydın-Buharkent & Ușak-Merkez & 0.945 & 0.897 & 0.901 \\
\hline Balıkesir-Dursunbey & Ușak-Merkez & 0.924 & 0.904 & 0.912 \\
\hline Eskișehir-Seyitgazi & Ușak-Merkez & 0.936 & 0.842 & 0.875 \\
\hline Kütahya-Gediz & Ușak-Merkez & 0.914 & 0.839 & 0.938 \\
\hline Kütahya-Simav & Ușak-Merkez & 0.911 & 0.867 & 0.855 \\
\hline Kütahya-Tavşanlı & Ușak-Merkez & 0.898 & 0.881 & 0.864 \\
\hline Kütahya-Dumlupınar & Ușak-Merkez & 0.920 & 0.903 & 0.875 \\
\hline Manisa-Alaşehir & Ușak-Merkez & 0.915 & 0.887 & 0.908 \\
\hline Manisa-Demirci & Ușak-Merkez & 0.897 & 0.928 & 0.832 \\
\hline Ușak-Eşme & Ușak-Merkez & 0.944 & 0.891 & 0.847 \\
\hline
\end{tabular}

Şekil 5, Afyon Dinar istasyon modeli kullanılarak elde edilen tahmin ve hedef değerler arasına çizilmiş doğrusal regresyon eğrilerini göstermektedir. Yüksek regresyon katsayıları

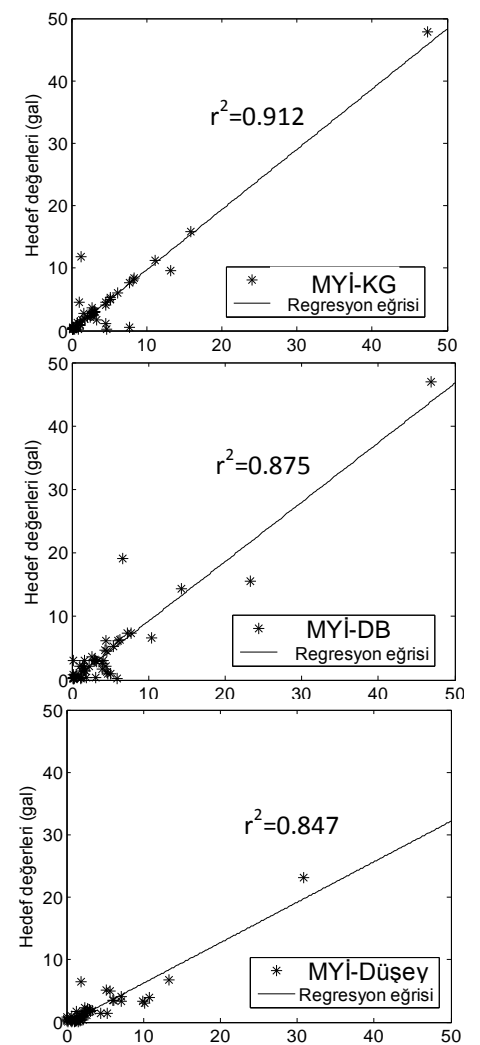

Şekil 5. Doğrusal regresyon eğrileri göstermektedir ki, Uşak çevresinde meydana gelmiș depremlerin YSA modelleri, Uşak'taki ya da istasyon olmayan herhangi bir koordinattaki MYİ değerlerini tahmin edebilecektir.

\subsection{Deprem Yönetmeliği ile Karşılaştırma}

Maksimum yer ivmesi (MYI) değerinin, etkin yer ivmesi katsayısı $\left(A_{0}\right)$ şeklinde ifade edildiği DBYBHY 2007'de yer alan tasarım deprem spektrumunda; 2. derece deprem bölgeleri için etkin yer ivmesi katsayısı 0.3 iken, 1 . derece deprem bölgeleri için bu değer 0.4'tür [1]. $A_{0}$ ile MYİ arasındaki ilişki (6) no'lu eşitlikte verilmektedir.

$$
M Y \dot{I}=A_{0} g
$$

Burada $g$, yerçekimi ivmesidir. Tüm ilçelerdeki YSA tahminleri Şekil 6(a)'da gösterilmiştir. En yüksek MYI değerleri Manisa-Demirci modeli ile elde edilmiștir. Șekil 6(b)'de ise tahmin değerlerinin ortalaması ve standart sapması gösterilmiş olup, DBYBHY 2007'de öngörülen ve UDAP-Ç-13-06 proje çıtılarına [32] göre oluşturulan haritadan elde edilen ivme değerleri ile karşılaștırma yapılmıştır. UDAP-Ç-13-06 projesi, özetle, güncel deprem haritaları oluşturmak amacıyla hazırlanmıştır. AFAD İnteraktif Türkiye Deprem 

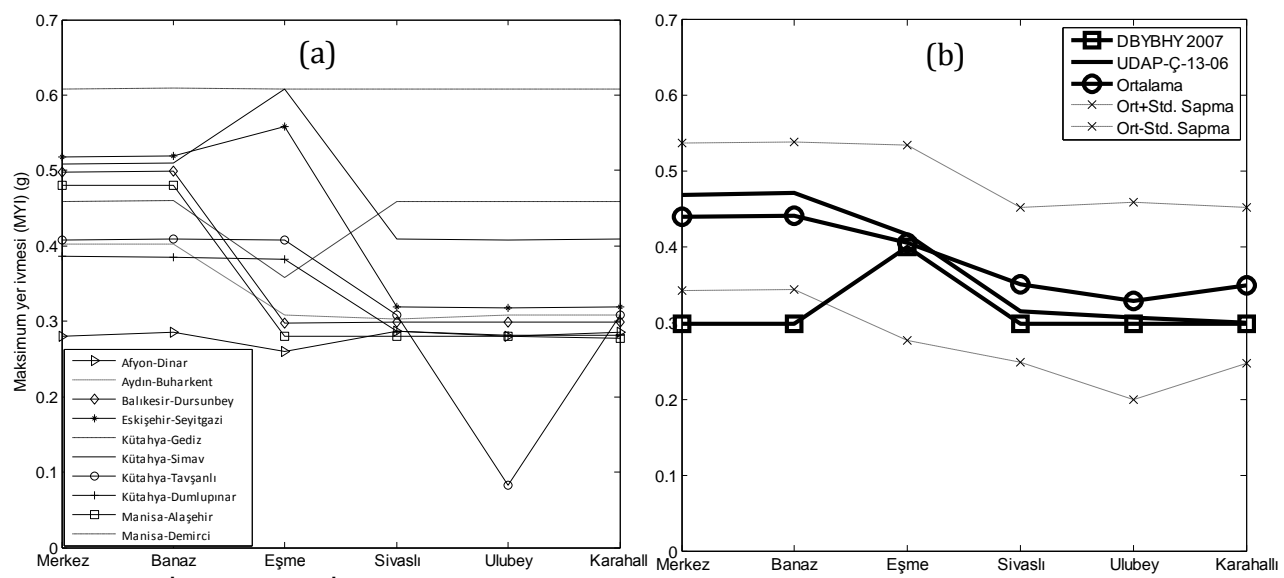

Șekil 6. (a) İlçelerin MYI değerleri (b) YSA ortalama değerleri, DBYBHY 2007 ve UDAP-Ç-13-06 proje çıktılarına göre MYİ'nin karşılaştırması

Tehlike Haritaları internet uygulamasindan [33], bu makalenin çalışma alanı olan Uşak ili incelenmiş ve MYI değerleri okunmuştur. Grafiksel gösterime ek olarak Tablo 4'de güncel haritadan (UDAP-Ç-13-06 proje çıktısı), yürürlükteki yönetmelikten (DBYBHY 2007) ve çalışma sonucunda elde edilen YSA modellerinden elde edilen MYİ değerleri karşılaştırılmıştır. Sonuçlar, DBYBHY 2007'deki, deprem bölgelerine göre belirlenen etkin yer ivmesi katsayıları $\left(\mathrm{A}_{0}\right)$ için öngörülen 50 yılda aşılma olasılı̆̆ı \%10 (tekrarlanma periyodu 475 yll) olan depremler içindir.

Tablo 4. UDAP-C-13-06 proje çktıları, DBYBHY ve YSA modellerinin MYI bakımından karșılaștırılması

\begin{tabular}{|l|c|c|c|}
\hline \multirow{2}{*}{ İlçeler } & \multicolumn{3}{|c|}{ MYİ (g) } \\
\cline { 2 - 4 } & $\begin{array}{c}\text { UDAP-Ç- } \\
13-06, \\
2016\end{array}$ & $\begin{array}{c}\text { DBYBHY, } \\
2007\end{array}$ & $\begin{array}{c}\text { YSA } \\
\text { (Ort.) }\end{array}$ \\
\hline Merkez & 0.469 & 0.300 & 0.441 \\
\hline Banaz & 0.472 & 0.300 & 0.442 \\
\hline Eşme & 0.417 & 0.400 & 0.406 \\
\hline Sivaslı & 0.316 & 0.300 & 0.351 \\
\hline Ulubey & 0.307 & 0.300 & 0.329 \\
\hline Karahallı & 0.301 & 0.300 & 0.350 \\
\hline
\end{tabular}

MYİ sonuçları, yürürlükteki yönetmelikten daha büyük değerlerde

çıkmış olmasına karşın, güncellenmiş Türkiye Deprem Tehlike Haritası'ndan elde edilen elde edilen sonuçlar ile yakın benzerlik göstermektedir.

\section{Tartışma ve Sonuç}

Deprem kayıt istasyonlarında verilerin kesintisiz bir şekilde toplanması ve olası bir kesinti durumunda hızlıca müdahale edilmesi teknik bilgi ve eleman ihtiyacı gerektirmektedir. Bu koșulların yeterli ölçüde sağlandığı noktalarda istasyonlar kurulmaktadır. Ancak maliyetli bir işlem de olduğundan, Türkiye genelini göz önünde tuttuğumuzda, istasyon bulunmayan bölgelerin sayısının oldukça fazla olduğunu söyleyebiliriz. Yapay sinir ağları yöntemi kullanılarak, ölçüm yapılmış istasyonların verileri modellenmekte ve veri gereken koordinatlarda başarılı tahminler yapılabilmektedir.

$\mathrm{Bu}$ çalıșmada, Ușak ili ve yakın çevresindeki her bir deprem istasyonu YSA ile modellenmiștir. Girdi katmanına, depremlerin derinliği, büyüklüğü ve istasyona olan uzaklıkları tanımlanarak, çıtı katmanından maksimum ivme verileri elde edilmiștir. Modellerin doğruluğunu tayin etmek amacıyla, istasyonun bulunduğu Uşak merkezde ölçülmüş deprem ivmeleri, 11 istasyondan 3 deprem bileșeni için oluşturulmuş YSA modelleri 
kullanılarak tahmin edilmiş MYİ değerleri ile kıyaslanmıştır. Doğrusal regresyon katsayılarının istatistiksel anlamda yüksek olması modellerin doğru çalıştığını gösteren önemli bir parametre olarak ele alınmıştır. Daha sonra, Uşak dışında bulunan 10 adet istasyonun modelleri kullanılarak, istasyon olmayan ilçelerdeki MYİ tahminleri de yapılmıştır. Tüm ilçeler için en yüksek MYI tahmin değerleri Manisa Demirci modeli kullanılarak 0.6g civarında elde edilmiştir. Elde edilen sonuçlar ve ortalama değerleri, DBYBHY 2007'de deprem bölgelerine göre öngörülen etkin yer ivmeleri ve güncel Türkiye Deprem Tehlike Haritaları'ndan ölçülen değerler ile klyaslanmıştır. Ortalama sonuçların, 2007'de öngörülen etkin yer ivmelerinden daha yüksek çıktı̆̆ ve güncel harita değerleri ile uyum içinde olduğu görülmektedir. Bu da çalışmadan elde edilen sonuçların ve bu sonuçlara ulaşmak için kullanılan yöntemin doğruluğunu göstermek açısından önemli bir sonuçtur.

Çalışma, sismik veri analizinde YSA yaklaşımı ve deprem şartnamelerindeki tasarım ivme değerlerinin güncellenmesi konularını içeren çalışmalara kaynak olarak gösterilebilecektir.

\section{Kaynakça}

[1] DBYBHY (2007). Deprem Bölgelerinde Yapılacak Binalar Hakkında Yönetmelik, Resmi Gazete Tarihi: 06.03.2007, Resmi Gazete Sayısı: 26454, Ankara, Türkiye.

[2] Türkiye Deprem Bölgeleri Haritası (1996). Bayındırlık ve İskan Bakanlığı, Afet İșleri Genel Müdürlüğü, Deprem Araştırma Dairesi Başkanlığı, Ankara, Türkiye.

[3] Atkinson, G.M., Boore, D.M. 2006. Earthquake ground-motion prediction equations for eastern
North America, Bulletin of the Seismological Society of America, Cilt 96, Sayı 6, s.2181-2205.

[4] Boore, D.M., Joyner, W.B., Fumal, T.E. 1997. Equations for estimating horizontal response spectra and peak acceleration from western North American earthquakes: a summary of recent work, Seismological Research Letters,Cilt 68, Sayl 1, s.128-153.

[5] Campbell, K.W. 1997. Empirical near-source attenuation relationships for horizontal and vertical components of peak ground acceleration, peak ground velocity, and pseudo-absolute acceleration response spectra, Seismological Research Letters, Cilt 68, Sayı 1, s.54-179.

[6] Spudich, P., Fletcher, J.B., Hellweg, M. 1997. SEA96-a new predictive relation for earthquake ground motions in extensional tectonic regimes, Seismological Research Letters, Cilt 68, Sayı 1, s.190-198.

[7] Ambraseys, N.N., Simpson, K.A., Bommer, J.J. 1996. Prediction of horizontal response spectra in Europe, Earthquake Engineering and Structural Dynamics, Cilt 25, Sayı 4, s.371-400.

[8] Alavi, A.H., Gandomi, A.H. 2011. Prediction of principal groundmotion parameters using a hybrid method coupling artificial neural networks and simulated annealing, Computers and Structures Cilt 89 (23-24), s.2176-2194.

[9] Gandomi, A.H., Alavi, A.H., Mousavi, M., Tabatabaei, S.M. 2011. A hybrid computational approach to derive new ground-motion attenuation models, Engineering Applications of Artificial Intelligence, Cilt 24 (4), s.717-732.

[10] Gullu, H., Ercelebi, E. 2007. A neural network approach for attenuation relationships: an application using 
strongegroundemotion data from Turkey, Engineering Geology, Cilt 93, s.65-81.

[11] Bojorquez, E., Bojorquez, J., Ruiz, S.E., Reyes-Salazar, A. 2012. Prediction of inelastic response spectra using artificial neural Networks, Mathematical Problems in Engineering, Cilt 2012, Article ID 937480, 15 pages, DOİ:10.1155/2012/937480.

[12] Panakkat, A., Adeli. 2007. Neural Network Models for Earthquake Magnitude Prediction Using Multiple Seismicity Indicators, International Journal of Neural Systems, Cilt 17, Sayı 1. DOI: http://dx.doi.org/10.1142/S01290 65707000890.

[13] Yuen, K.V., Mu, H.Q. 2011. Peak Ground Acceleration Estimation by Linear and Nonlinear Models with Reduced Order Monte Carlo Simulation, Computer-Aided Civil and Infrastructure Engineering, Cilt 26, s.30-47.

[14] Kamatchi, P., Rajasankar, J., Ramana, G.V., Nagpal, A.K. 2010. A neural network based methodology to predict sitespecific spectral acceleration values, Earthquake Engineering and Engineering Vibration, Cilt 9, Sayl 4, s.459-472.

[15] Derras, B., Bard, P.Y., Cotton, F., Bekkouche, A. 2012. Adapting the neural network approach to PGA prediction: an example based on the KiK-net data, Bulletin of the Seismological Society of America, Cilt 102, Sayı 4, s. 1446-146. DOİ: 10.1785/0120110088.

[16] Pozos-Estrada, A., Gomez, R., Hong, H.P. 2014. Use of Neural Network to Predict the Peak Ground Accelerations and Pseudo Spectral Accelerations for Mexican Inslab and Interplate Earthquakes, Geofisica Internacional, Cilt 53, s.39-57.
[17] Gandomi, M., Soltanpour, M., Zolfaghari, M., Gandomi, A.H. 2016. Prediction of Peak Ground Acceleration of Iran's Tectonic Regions using a Hybrid Soft Computing Technique, Geoscience Frontiers, Cilt 7, s.75-82.

[18] Kia, A., Sensoy, S. 2014. Assessment the Effective Ground Motion Parameters on Seismic Performance of $\mathrm{R} / \mathrm{C}$ Buildings Using Artificial Neural Network, Indian Journal of Science and Technology, Cilt 7, s.2076-2082.

[19] Thomas, S., Pillai G.N., Pal, K. 2016. Prediction of peak ground acceleration using $\epsilon$-SVR, $v$-SVR and Ls-SVR algorithm, Geomatics, Natural Hazards and Risk, DOI: 10.1080/19475705.2016.1176604.

[20] Kerh, T., Ting, S.B. 2005. Neural network estimation of ground peak acceleration at stations along Taiwan high-speed rail system, Engineering Applications of Artificial Intelligence, Cilt 18, s.857-866.

[21] Gandomi, M., Soltanpour, M., Zolfaghari, M.R., Gandomi, A.H. 2016. Prediction of peak ground acceleration of Iran's tectonic regions using a hybrid soft computing technique, Geoscience Frontiers, Cilt 7, s.75-82.

[22] Lee, S.C., Han, S.W. 2002. Neuralnetwork-based models for generating artificial earthquakes and response spectra, Computers \& Structures, Cilt 80, Sayı 20-21, s.1627-1638.

[23] Garcia, S.R., Romo, M.P., Mayoral, J.M. 2007. Estimation of peak ground accelerations for Mexican subduction zone earthquakes using neural networks, Geofisica Internacional, Cilt 46, Sayı 1, s.5163.

[24] Günaydın, K., Günaydın, A. 2008. Peak ground acceleration prediction by artificial neural 
networks for northwestern Turkey, Mathematical Problems in Engineering, Cilt 2008, Article ID 919420, 20 pages.

[25] Arjun, C.R., Kumar, A. 2009. Artificial neural network-based estimation of peak ground acceleration, Journal of Earthquake Technology, Cilt 46, s.19-28.

[26] http://www.bilgiustam.com/beyni n-sirlari/ (Erişim Tarihi: 20.08.2015).

[27] SSen, Z. 2004. Yapay Sinir Ağları İlkeleri, İstanbul Su Vakfi

[28] Mehrotra, K., Mohan, C.K., Ranka S. 2000. Elements of Artificial Neural Network, USA MIT Press.

[29] Türkiye Ulusal Kuvvetli Yer Hareketi Veri Tabanı. http://kyhdata.deprem.gov.tr/2K/ kyhdata_v4.php

[30] Papazachos, B. C., Kiratzi, A. A., Karakostas, B. G. 1997. Towards a Homogeneous Moment-magnitude Determination for Earthquakes in Greece and the Surrounding Area, Bulletin of the Seismological Society of America, Cilt 87, s.474483.

[31] Ma, L., Xu, F., Wang, X., Tang, L. 2010. Earthquake Prediction Based on Levenberg-Marquardt Algorithm Constrained BackPropagation Neural Network Using DEMETER Data, Knowledge Science, Engineering and Management, 4th International Conference, KSEM 2010, Belfast, Northern Ireland, UK, September $1-3$, 2010. Proceedings. DOI: 10.1007/978-3-642-15280-1_57.

[32] Ulusal Deprem Araștırma Programı, UDAP-Ç-13-06 Türkiye Sismik Tehlike Haritasının Güncellenmesi, Aralık 2014, Ankara.

[33] Türkiye Deprem Tehlike Haritaları İnteraktif Web Uygulaması. https://testtdth.afad.gov.tr/ 